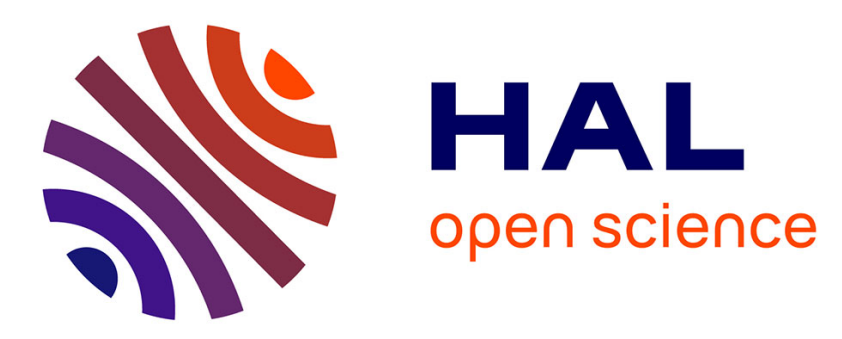

\title{
Terpene evolution during the development of Vitis vinifera L. cv. Shiraz grapes
}

Pangzhen Zhang, Sigfredo Fuentes, Tracey Siebert, Mark Krstic, Markus

Herderich, Edward William R. Barlow, Kate Howell

\section{- To cite this version:}

Pangzhen Zhang, Sigfredo Fuentes, Tracey Siebert, Mark Krstic, Markus Herderich, et al.. Terpene evolution during the development of Vitis vinifera L. cv. Shiraz grapes. Food Chemistry, 2016, 204, pp.463-474. 10.1016/j.foodchem.2016.02.125 . hal-01837778

\section{HAL Id: hal-01837778 \\ https://hal.science/hal-01837778}

Submitted on 28 May 2020

HAL is a multi-disciplinary open access archive for the deposit and dissemination of scientific research documents, whether they are published or not. The documents may come from teaching and research institutions in France or abroad, or from public or private research centers.
L'archive ouverte pluridisciplinaire HAL, est destinée au dépôt et à la diffusion de documents scientifiques de niveau recherche, publiés ou non, émanant des établissements d'enseignement et de recherche français ou étrangers, des laboratoires publics ou privés. 


\section{Accepted Manuscript}

Terpene evolution during the development of Vitis vinifera L. cv. Shiraz grapes

Pangzhen Zhang, Sigfredo Fuentes, Tracey Siebert, Mark Krstic, Markus

Herderich, Edward William R. Barlow, Kate Howell

PII:

S0308-8146(16)30293-X

DOI: http://dx.doi.org/10.1016/j.foodchem.2016.02.125

Reference: FOCH 18846

To appear in:

Food Chemistry

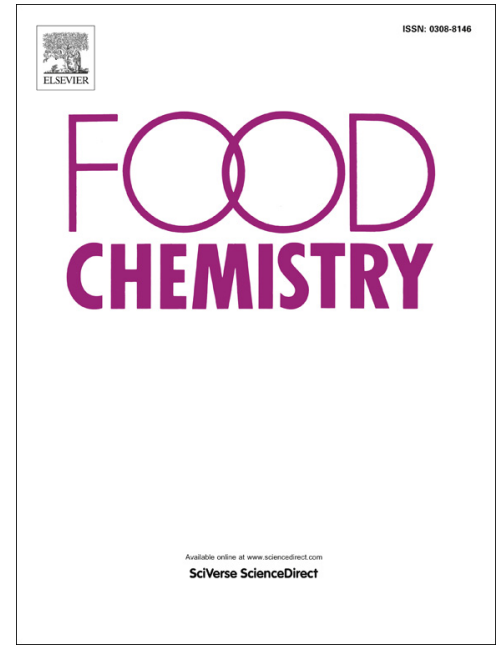

Received Date: $\quad 5$ July 2015

Revised Date: $\quad 14$ December 2015

Accepted Date: $\quad 19$ February 2016

Please cite this article as: Zhang, P., Fuentes, S., Siebert, T., Krstic, M., Herderich, M., Barlow, E.W.R., Howell, K., Terpene evolution during the development of Vitis vinifera L. cv. Shiraz grapes, Food Chemistry (2016), doi: http://dx.doi.org/10.1016/j.foodchem.2016.02.125

This is a PDF file of an unedited manuscript that has been accepted for publication. As a service to our customers we are providing this early version of the manuscript. The manuscript will undergo copyediting, typesetting, and review of the resulting proof before it is published in its final form. Please note that during the production process errors may be discovered which could affect the content, and all legal disclaimers that apply to the journal pertain. 
1 Original research article

2 Terpene evolution during the development of Vitis vinifera L. cv. Shiraz grapes

3

$4 \quad$ Pangzhen Zhang ${ }^{\mathrm{a}}$, Sigfredo Fuentes ${ }^{\mathrm{a}}$, Tracey Siebert ${ }^{\mathrm{b}}$, Mark Krstic ${ }^{\mathrm{c}}$, Markus

5 Herderich $^{\mathrm{b}}$, Edward William R. Barlow ${ }^{\mathrm{a}}$ and Kate Howell ${ }^{\mathrm{a}, \mathrm{d}}$ *

6

$7 \quad$ a Faculty of Veterinary and Agricultural Sciences, University of Melbourne, Parkville, Vic 3010, Australia

$9 \quad{ }^{b}$ Australian Wine Research Institute, Urrbrae, SA 5064, Australia

$10{ }^{\mathrm{c}}$ Australian Wine Research Institute, Mooroolbark, Vic 3138, Australia

$11{ }^{d}$ INRA, UMR1083 SPO, 2, Place Viala, F-34060, Montpellier, France.

14 * corresponding author: Tel: +61 3 90353119; email address:

15 khowell@unimelb.edu.au

17 Running title: Terpene evolution in Shiraz grape development 


\section{Abstract}

The flavour of wine is derived, in part, from the flavour compounds present in the grape, which change as the grapes accumulate sugar and ripen. Grape berry terpene concentrations may vary at different stages of berry development. This study aimed to investigate terpene evolution in grape berries from four weeks postflowering to maturity. Grape bunches were sampled at fortnightly intervals over two vintages (2012-13 and 2013-14). In total, five monoterpenoids, 24 sesquiterpenes, and four norisoprenoids were detected in grape samples. The highest concentrations of total monoterpenoids, total sesquiterpenes, and total norisoprenoids in grapes were all observed at pre-veraison. Terpenes derived from the same biosynthetic pathway had a similar production pattern during berry development. Terpenes in grapes at harvest might not necessarily be synthesised at post-veraison, since the compounds or their precursors may already exist in grapes at pre-veraison, with the veraison to harvest period functioning to convert these precursors into final products.

Keywords: rotundone, terpene, sesquiterpene, grape ripening

\section{Highlights}

- Pre-veraison berries contain the highest total terpenoid concentrations

- Berries at different developmental stages have different terpene profiles

- Terpene biosynthesis pathways dictate production patterns during berry development

- Rotundone was present in Shiraz flower caps and grapes at both pre-veraison and post-veraison 


\section{Introduction}

44 Grape berries contain hundreds of compounds that contribute to wine flavour and aroma. Most of these grape compounds exist as odourless, glycosidically-bound forms that are hydrolysed into active aroma compounds during fermentation or storage (Hjelmeland \& Ebeler, 2015). However, some compounds in grapes, such as certain terpenes, may undergo minimal or no alteration and are directly linked to wine aroma (Dunlevy, Kalua, Keyzers, \& Boss, 2009). The majority of identified terpenes that contribute to grape and wine flavour and aroma belong to the monoterpenes (monoterpenoids) sub-family, and only one sesquiterpene sub-family member is reported to be important for wine aroma and flavour (Dunlevy, et al., 2009). The oxygenated bicyclic sesquiterpene, named rotundone, gives grapes and wine a 'black pepper' character (Wood, et al., 2008) and is stylistically important to

55 the 'terroir' of some cool climate Australian wine regions (Herderich, et al., 2012).

56 Rotundone can be formed by aerial oxidation and biosynthesis from a precursor 57 compound, $\alpha$-guaiene (Huang, Burrett, Sefton, \& Taylor, 2014; Takase, et al., 2015).

58 The discovery of rotundone has directed attention to the importance of 59 sesquiterpene flavours; however, there is only limited research on sesquiterpene 60 production in grapes.

Grape terpene production varies at different berry developmental stages: preveraison, the lag phase, and post-veraison (Kalua \& Boss, 2009). In west Victoria

64 (Australia), Shiraz grapevines start their annual cycle around late 65 September/October, when dormant vines undergo bud burst and start to grow. In this 66 region, Shiraz fruit set typically occurs from early to middle December, when berries 67 experience a period of rapid cell division and slight cell expansion (pre-veraison) 
68 before entering the lag phase of minimal berry growth during early January. At the

69 end of the lag phase (late January to early February in this region), berries go 70 through veraison with cell expansion, berry softening, and colour change 71 (Gladstones, 2004). For Shiraz, harvest ripeness typically occurs from the middle of 72 March to early April in this region, but usually in middle to late April in our study 73 vineyard (P. Zhang, Barlow, Krstic, Herderich, Fuentes, \& Howell, 2015; Pangzhen 74 Zhang, Howell, Krstic, Herderich, Barlow, \& Fuentes, 2015). The post-veraison to 75 harvest period is critical for quality grape production, since grape berries rapidly compounds (Gladstones, 2004).

Most previous studies on the development period-specific evolution of grape volatiles and terpenes have focused on the post-veraison to harvest period. A previous study reported that the total monoterpene concentration reaches its maximum at intermediate-ripe at $6-8^{\circ}$ Baumé in Airen, and at around $11^{\circ}$ Baumé in Chardonnay and Macabeo (García, Chacón, Martínez, \& Izquierdo, 2003). However, norisoprenoids and monoterpenes concentrations have increase with grape maturation in Pinot noir grapes (Fang \& Qian, 2006). In Vitis vinifera L. cv 'Fernão-

86 Pires' grapes, 16 monoterpenes and two norisoprenoids were detected in grapes 87 from veraison to harvest, which reached maximum concentrations at intermediate88 ripe (Coelho, Rocha, Barros, Delgadillo, \& Coimbra, 2007). Another study reported 89 that bicylic sesquiterpene concentrations increased from half-veraison to harvest in 90 Riesling, Lemberger, Shiraz, and Yellow Muscat, while acyclic sesquiterpene 91 concentrations decreased (May \& Wüst, 2012). However, only 13 sesquiterpenes 92 were identified in this study, with nine observed in Shiraz. A more comprehensive 
study on sesquiterpene composition in Vitis vinifera L. cV. Baga found that most sesquiterpenes, including a-guaiene, continuously increased from intermediate-ripe to post-maturation (Coelho, Rocha, Delgadillo, \& Coimbra, 2006). In Cabernet Sauvignon, two monoterpenes and seven sesquiterpenes were identified at preveraison, but no terpenoids were observed at veraison and post-veraison (Kalua, et al., 2009; Kalua \& Boss, 2010). The same study reported monoterpenes and sesquiterpenes in Riesling grapes at both pre-veraison and post-veraison, but not at veraison. Studies that have investigated rotundone accumulation in grapes after veraison demonstrated that it mainly accumulates after intermediate ripeness (Geffroy, Dufourcq, Carcenac, Siebert, Herderich, \& Serrano, 2014; Pangzhen Zhang, et al., 2015). An understanding of sesquiterpene accumulation during berry development, especially prior to veraison, is lacking, and a detailed study on sesquiterpene evolution throughout the berry development stages is required.

Here, we fill this information gap and explore terpene evolution, especially the less well-studied but important sesquiterpenes, in grapes. Terpene profiles in Shiraz grapes were measured from early berry formation to late ripening. These data are useful for manipulation of compound production, such as rotundone, to improve wine aroma.

\section{Materials and methods}

\subsection{Chemicals}

Rotundone ((3S,5R,8S)-3,4,5,6,7,8-hexahydro-3,8-dimethyl-5-(prop-1-en-2-yl)$1(2 \mathrm{H})$-azulenone) and ${ }^{2} \mathrm{H}_{5}$-rotundone were synthesised as previously described (Siebert, Wood, Elsey, \& Pollnitz, 2008; Wood, et al., 2008). A reference standard of 
118

119

120

121

122

123

124

125

126

127

128

129

130

131

132

133

134

$\alpha$-copaene was supplied by Sigma-Aldrich (Castile Hill, NSW, Australia). Working solutions of standards were prepared volumetrically in ethanol and stored at $4^{\circ} \mathrm{C}$ until required. High-performance liquid chromatography (HPLC)-grade ethyl acetate, npentane, methanol, and ethanol were obtained from Rowe Scientific (Doveton, Vic, Australia). Analytical-grade potassium L-tartrate monobasic, tartaric acid, and other chemicals were obtained from Sigma-Aldrich. Water was purified using the Milli-Q system (Millipore Australia, Bayswater, Victoria, Australia).

\subsection{Vineyard site}

The study was conducted in a commercial vineyard (The Old Block, Mount Langi Ghiran $\left.37.31^{\circ} \mathrm{S}, 143.15^{\circ} \mathrm{E}\right)$ located in the Grampians wine region of Victoria, Australia. The vineyard is approximately $15.5 \mathrm{~km}$ east of the nearest Bureau of Meteorology (BOM) weather station at Ararat Prison (Australian BOM Station No. 089085). The long-term mean January temperature (MJT) recorded at this weather station is $19.1^{\circ} \mathrm{C}$, with annual average rainfall of $584.2 \mathrm{~mm}$ by February 2015: it is classified as a cool climate wine region (Gladstones, 2004). The MJT and total rainfall from October to harvest for the two studied growing seasons (2012-13 and 2013-14) were $20.0^{\circ} \mathrm{C}, 124.1 \mathrm{~mm}$ and $21.7^{\circ} \mathrm{C}, 140.9 \mathrm{~mm}$, respectively (Table S-1). The vineyard was planted in 1968 with Vitis vinifera, cv. Shiraz on its own roots, 3.0 $\mathrm{m}$ between rows and $1.8 \mathrm{~m}$ between vines, with rows oriented northeast to southwest. Grapevines were trained to a vertical shoot positioned (VSP) trellis, and a dripping irrigation system was installed along vineyard rows with a dripper spacing of $0.5 \mathrm{~m}$ and dipper output of 1.5 litres per hour. Grapevines were irrigated when required at a rate of $5.76 \mathrm{~L} /(\mathrm{hr} \cdot \mathrm{vine})$. The total irrigation volumes from October to harvest in the two studied growing season seasons (2012-13 and 2013-14) were 
$14384.3 \mathrm{~mm}$ and $60.8 \mathrm{~mm}$, respectively. No significant pest or disease pressure was

144 observed during the experimental seasons.

2.3. Evaluation of rotundone evolution during grape development

147 Shiraz grapes were sampled in triplicate (2 $\mathrm{kg}$ per field replicate) at fortnightly 148 intervals from four weeks post-flowering (wpf) until commercial harvest in two 149 consecutive growing seasons (2012-13 and 2013-14). The wpf was counted from the 150 time of a minimum of $80 \%$ cap-fall, grapevine growth stage E-L 25-26 (Pearce \& 151 Coombe, 2004). Grape bunch samples were randomly collected from different grapevines across the vineyard ( $n>30$ grapevines) on each sampling date. In the 2013-14 growing season, samples were also collected at $80 \%$ caps off (E-L25) on 11 December 2013. Final sampling was conducted at the beginning of commercial harvest on 10 April 2013 and 8 April 2014, respectively. Commercial harvest was performed between 9 and 16 April 2013 and between 8 and 17 April 2014 with selective hand harvest first followed by machine harvest at later dates. Grape samples were collected in zip-lock plastic bags, frozen at $-20^{\circ} \mathrm{C}$, transferred to the laboratory in Styrofoam boxes on dry ice, and stored at $-20^{\circ} \mathrm{C}$ before analysis. Total soluble solids (TSS), titratable acidity (TA), and the $\mathrm{pH}$ of bunch samples were analysed using a refractometer, alkaline titration, and a $\mathrm{pH}$ meter, respectively, following published protocols (Iland, 2004).

2.4. Preparation of samples and solid-phase microextraction-gas chromatographymultidimenstional mass spectrometery (SPME-MDGC-MS ) rotundone analysis 
sub-sampled before being homogenised with a hand-held blender. Sub-samples were centrifuged to separate solids and liquids. The solids were mixed with $30 \mathrm{ml}$ ethanol, $30 \mathrm{ml}$ water, and $100 \mu \mathrm{d} 5$-rotundone $(516 \mathrm{ng} / \mathrm{ml}$ in ethanol) as internal standard, then shaken for $24 \mathrm{~h}$ at $22^{\circ} \mathrm{C}$ and sonicated before reintroducing the juice. Sub-samples were then centrifuged and filtered $(1.6 \mu \mathrm{m}$ glass fibre) to obtain berry extract filtrate, which was topped up to $200 \mathrm{ml}$ with deionised water prior to solid phase extraction (SPE) performed as reported previously (Siebert, et al., 2008). The SPE residue supernatant was air dried with nitrogen and reconstituted in $0.5 \mathrm{ml}$ ethanol and $9 \mathrm{ml}$ deionised water. The samples were then analysed by SPME-GCMS in the Australian Wine Research Institute (AWRI) following established protocols (Geffroy, et al., 2014).

\subsection{Terpenoid analysis}

Terpenoid analysis was conducted for grape samples of 2013-14 vintage based on a published protocol (Parker, Pollnitz, Cozzolino, Francis, \& Herderich, 2007) with the following modifications. An Agilent Technologies 6890 gas chromatograph (GC; Agilent Technologies, Santa Clara, CA) was equipped with a Gerstel MPS2 multipurpose sampler and coupled to an Agilent 5973 mass selective detector (MSD). The instruments were controlled using Agilent G1701EA MSD ChemStation software in conjunction with Gerstel Maestro software (version 1.4.20.0). The GC was fitted with a J\&W DB-5ms capillary column measuring approximately $30 \mathrm{~m} \times 0.25 \mathrm{~mm}$, $0.25 \mu \mathrm{m}$ film df. The carrier gas was helium (ultrahigh purity, BOC, Adelaide, SA, Australia), and the flow rate was $1.0 \mathrm{ml} / \mathrm{min}$ in constant flow mode. The GC inlet was fitted with a resilanised borosilicate glass SPME inlet liner (Supelco, $6.5 \mathrm{~mm}$ o.d., $0.75 \mathrm{~mm}$ i.d., $78.5 \mathrm{~mm}$ long) held at $220^{\circ} \mathrm{C}$. 
194 The SPME fibre was desorbed in the pulsed splitless mode and the splitter, at 50:1,

202 was opened after $30 \mathrm{~s}$. The fibre was allowed to bake in the inlet for $10 \mathrm{~min}$. The oven was started at $50^{\circ} \mathrm{C}$, held for $1 \mathrm{~min}$, increased to $230^{\circ} \mathrm{C}$ at $3^{\circ} \mathrm{C} / \mathrm{min}$, then increased to $280^{\circ} \mathrm{C}$ at $20^{\circ} \mathrm{C} / \mathrm{min}$ and held at $280^{\circ} \mathrm{C}$ for $5 \mathrm{~min}$. The MS transfer line was held at $250^{\circ} \mathrm{C}$. The temperatures of the MS source and quadruple were $230^{\circ} \mathrm{C}$ and $150^{\circ} \mathrm{C}$, respectively. The MS was operated in positive $\mathrm{El}$ mode at $70 \mathrm{eV}$ with simultaneous selected ion monitoring (SIM) and scanning over a mass acquisition range of $35-280 \mathrm{~m} / \mathrm{z}$.

$100 \mathrm{~g}$ of de-stemmed grapes were sub-sampled before being homogenised using a hand-held blender. $5 \mathrm{~g}$ of homogenised sample was transferred into a HS-SPME vial (Agilent Technologies, 20ml) and mixed with $500 \mu \mathrm{L} \alpha$-copaene $(200.64 \mu \mathrm{g} / \mathrm{L}$ in ethanol) as internal standard. The samples were then shaken for $24 \mathrm{~h}$ at $22^{\circ} \mathrm{C}$ before adding $2 \mathrm{ml}$ saturated brine and being subjected to SPME-GC-MS analysis. The vial and its contents were heated to $45^{\circ} \mathrm{C}$. A polydimethylsiloxane/divinylbenzene (PDMS/DVB, Agilent) $65 \mu \mathrm{m}$ SPME fibre was exposed to the headspace for $60 \mathrm{~min}$ with agitation. Sesquiterpenes were identified by comparing the mass spectra and retention indices with the terpenoids library in MassFinder (version 4.1, Dr Hochmuth Scientific Consulting, Hamburg, Germany). All compounds except $\alpha$-guaiene were semi-quantified as $\alpha$-copaene equivalents, expressed as relative areas $\times 100$. It is therefore difficult to compare these semi-quantitative values with values in other studies. $\alpha$-guaiene was determined by SIM with $\alpha$-copaene as internal standard; the ions monitored were: $\mathrm{m} / \mathrm{z} 105,133,147,161$, and 204 ; dwell time $25 \mathrm{~ms}$ each. The target ions were typically m/z 147 for $\alpha$-guaiene and 161 for $\alpha$-copaene with ions 105 , 
218 133, and $204 \mathrm{~m} / \mathrm{z}$ used as qualifiers. Data were analysed usingAgilent G1701DA

219

220

221

222

223

224

225

226

227

228

229

230

231

232

233

234

235

236

237

238

239

240

241

242

MSD ChemStation software. $\alpha$-guaiene was expressed as the ratio of $\mathrm{m} / \mathrm{z} 147: \mathrm{m} / \mathrm{z}$

161 multiplied by the concentration of $\alpha$-copaene internal standard. The assay precision was validated by a series of standard additions of internal standard as described previously (Parker, et al., 2007). Blank SPME runs and blank internal standards were checked regularly.

2.6. Statistical analysis

TSS, TA, $\mathrm{pH}$, and terpenoids in grape samples from different berry developmental stages were compared using one-way analysis of variance (ANOVA) at $p<0.05$ (CoStat, version 6.4, CoHort Software, Monterey, USA). Terpenoid concentrations at different berry developmental stages were analysed by discriminant analysis using SPSS v.21 (SPSS Inc., Chicago, IL. USA).

\section{Results and discussion}

\subsection{Berry development pattern differentiation}

Different grape berry developmental stages have previously been characterised using grape berry weight, ${ }^{\circ} \mathrm{Brix}, \mathrm{pH}$, and titratable acidity measurements (Table 1) (Coombe \& lland, 2004; Kalua, et al., 2009). In this study, veraison occurred between 10 and 11 wpf in both growing seasons. The 2013-14 harvest was brought forward due to heavy rain forecast in late April 2014 (harvest at 17 wpf) and, as a result, the grapes were less ripe than in the 2012-13 growing season (harvest at 18wpf). As expected, ${ }^{\circ}$ Brix and $\mathrm{pH}$ were lower and TA was higher in 2013-14 grapes. Initial measurements showed that there were fewer terpenes in grape samples at veraison compared to both pre- and post-veraison (Fig. 1). 
243 The differences in terpene profiles at different berry developmental stages were

244 analysed using discriminant analysis to identify terpene production patterns and the

245 most important compounds present at each developmental stage. Discriminant 246 analysis biplots (Fig. 2) were used to visualise terpene concentration patterns during 247 berry development, and most of the variance $(91.2 \%)$ was explained by the first two 248 discriminant functions. Fourteen variables were used in the classification functions, 249 including limonene, 1,8-cineole, geraniol, citronellol, clovene, $\alpha$-ylangene, $\beta$ 250 bourbonene, (E)- $\beta$-caryophyllene, $\beta$-copaene, $\alpha$-guaiene, theaspirane isomer $A$, 251 theaspirane isomer $\mathrm{B},(\mathrm{E})-\beta$-damascenone, $\beta$-lonone. These compounds were 252 shown to vary significantly among different grape ripening stages using ANOVA (See 253 Table 1 in Pangzhen Zhang, et al. ). Grape berries at 4 and 17 wpf were clearly 254 separated from the other developmental stages, while those at 6, 9, 13, 11 and 15 255 wpf clustered into one group. Within this cluster, 6 and 15 wpf tended to separate 256 from 9, 11 and 13 wp. This suggests that the terpenoid profiles changed rapidly and 257 markedly after fruit set between 4 and 6 wpf, but only slightly from 6 wpf to veraison 258 (9, 11, and $13 \mathrm{wpf})$. Terpene profiles changed slightly from veraison (9-13 wpf) to 259 intermediate-ripe (15 wpf), but rapidly towards 17 wpf. Thus, discriminant analysis 260 allowed us to categorise berry developmental stages into early, pre-veraison, 261 veraison, intermediate-ripe, and harvest, a useful frame of reference for 262 understanding terpene evolution during berry development.

264 3.2. Berry developmental stages and representative compounds

265 A visual inspection of terpenoid profiles indicated that berries contain different 266 terpenoids at different developmental stages (Fig. 1). Grape berries are terpene-rich, 267 and peaks were well separated at 4 wpf (Fig. 1a). The number and peak size 
268 dropped dramatically towards veraison (11 wpf) (Fig. 1b). However, there were more 269 compounds at relatively low abundance at harvest (17 wpf; Fig. 1c). We have 270 quantified the production of terpenoids based on relative amounts per $\mathrm{kg}$ in this study. We note that there may be some effects on the terpenoids concentration caused by the dilution from increased berry size and skin area. However, these changes won't affect the comparison of accumulation pattern among different metabolites. It is, therefore, reasonable to explore terpene evolution in grapes based on their developmental stages.

\subsubsection{Early berry developmental stage terpenoid profile (4 wpf)}

At the early developmental stage, berries appeared to be very capable of terpene production, as evidenced by the large numbers and high concentrations of terpenoids (Fig. 3a, Table 1 in Pangzhen Zhang, et al. ). Berries at this stage contained the highest concentration of total volatiles and terpenoids compared to all other stages, with the total terpenoid concentration accounting for $24.22 \%$ of the total volatiles detected in terms of GC peak area (Table 1 in Pangzhen Zhang, et al. ). The highest total monoterpenoid concentration was also observed at this stage, with geranyl acetone the most abundant monoterpenoid. Limonene was only observed at this stage, while 1,8-cineole (eucalyptol) and geraniol concentrations were significantly higher at this stage compared to other stages. The major sesquiterpenes observed at this stage were $\alpha$-humulene and $\beta$-caryophyllene, accounting for $33.88 \%$ and $29.95 \%$ of the total terpenoids (by GC peak area) respectively. This is consistent with a previous study that reported the highest concentrations of these two sesquiterpenes at early berry development in Cabernet

292 Sauvignon (Kalua, et al., 2009). In addition, ү-muurolene, $\alpha$-muurolene, $\delta$-cadinene, 
293 zonarene, $\omega$-cadinene, and $\alpha$-calacorene concentrations were also significantly 294 higher at this stage than at all other stages. However, in Cabernet Sauvignon, only y295 muurolene was observed at early-stage berry development (Kalua, et al., 2009). 296 Furthermore, epi-cubenol and cubenol were only observed at this stage. Four 297 isoprenoids were observed at this stage and accounted for $8.44 \%$ of the total 298 terpenoids.

299

\subsubsection{Pre-veraison terpenoid profile (6 wpf)}

At this stage, the terpenes were distant from those at 4 wpf in discriminant analysis

(Fig. 2), indicating that the terpenoid profiles had significantly changed between these two time points. Significant decreases in total volatiles and terpenoid concentrations were observed at this stage (Table 1 in Pangzhen Zhang, et al. ). The total monoterpenoids slightly decreased, while geranyl acetone remained the most abundant monoterpenoid. All monoterpenoid concentrations decreased except citronellol, which slightly increased. The total sesquiterpene concentration decreased dramatically to less than $1 / 6$ that of the previous stage, with $\alpha$-humulene and $\beta$ caryophyllene accounting for the majority of the decrease but remaining the most abundant sesquiterpenes. The concentrations of $\gamma$-muurolene, $\alpha$-muurolene, $\delta$ cadinene, zonarene, $\omega$-cadinene, and $\alpha$-calacorene all markedly decreased at this stage, while the concentration of $\alpha$-guaiene slightly increased and calamenene started to appear in the berries. The highest total norisoprenoid concentrations were

314 observed at this stage and accounted for $37.7 \%$ of the total terpenoids in terms of 315 GC peak area. Theaspirane isomer A was the most abundant norisoprenoid in terms 316 of GC peak area and accounted for $19.1 \%$ of the total terpenoids at this stage. 
317 Compared to the previous stage, the concentration of all norisoprenoids increased except $\beta$-ionone, which slightly decreased.

\subsubsection{Veraison terpenoid profile (9-13 wpf)}

321 This developmental stage was characterised by lower concentrations of total 322 volatiles and terpenoids (Table 1 in Pangzhen Zhang, et al. ), suggesting that the berries at this stage might have lost the ability to produce volatile compounds or that previously formed compounds had been converted into non-volatile forms. This was consistent with previous observations in Cabernet Sauvignon, in which the fewest and lowest concentrations of volatiles were observed at similar stages (Kalua, et al., 2009). The 1,8-cineole, geraniol, and geranyl acetone concentrations continued to decrease and reached their lowest concentrations at wpf 11, while citronellol was not detected from wpf 11 . Geraniol and geranyl acetone were previously observed at veraison in Vitis vinifera L. cv. Baga grapes (Coelho, et al., 2006) and, in the same study, limonene and citronellol were also detected at veraison. Geraniol, geranyl period, accounting for only $5.75 \%$ of the total terpenoids in terms of GC peak area at wpf 13. $\beta$-Caryophyllene was not detected from wpf 11 , while clovene re-appeared at wpf 11 . The concentrations of $\alpha$-guaiene, $\alpha$-humulene, $\delta$-cadinene, and calamenene decreased to very low levels, while $\gamma$-muurolene, $\alpha$-muurolene, and $\omega$-cadinene were not detected. The concentrations of zonarene and $\alpha$-calacorene continued to decrease to zero by the end of this period. Sesquiterpenes were not detected at 
342 veraison in Baga, Cabernet Sauvignon, and Riesling grapes (Coelho, et al., 2007;

343 Kalua, et al., 2009, 2010). The norisoprenoid concentration also decreased at this 344 stage, but not as much as monoterpenoids and sesquiterpenes. As a result, total norisoprenoids accounted for $71.54 \%$ of the total terpenoids in terms of GC peak area at 11 wpf. All four norisoprenoids were also detected in Baga grapes, while only $\beta$-damascenone and $\beta$-ionone were observed in 'Fernão-Pires' grapes at this stage 348 (Coelho, et al., 2007; Coelho, et al., 2006).

3.2.4. Intermediate ripeness terpenoid profile (15 wpf)

At this stage, the total volatile and terpenoid concentrations slightly increased but remained relatively low (Table 1 in Pangzhen Zhang, et al. ). The concentrations of all three monoterpenoids, 1,8-cineole, geraniol, and geranyl acetone, slightly increased. A slight increase in geraniol was also observed in Baga and 'Fernão-Pires' grapes at intermediate ripeness (Coelho, et al., 2007; Coelho, et al., 2006). The sesquiterpene concentrations, including clovene, $\alpha$-guaiene, $\alpha$-humulene, $\delta$ cadinene, and calamenene, remained low. $\alpha$-ylangene and epi-zonarene first appeared at this stage, paralleling a previous report in Baga (Coelho, et al., 2006).

The total norisoprenoid concentration slightly decreased, with $\beta$-damascenone not detected from this stage onwards. However, relatively higher norisoprenoid concentrations were observed at this stage in Baga and 'Fernão-Pires' grapes (Coelho, et al., 2007; Coelho, et al., 2006).

\subsubsection{Harvest terpenoid profile (17 wpf)}

The terpene profile at harvest was distant from intermediate ripeness in discriminant analysis (Fig. 2), indicating that the terpenoid profile significantly changed from 15 to 
36717 wpf. The total volatile concentration slightly decreased, while total terpenoids 368 increased during this period (Table 1 in Pangzhen Zhang, et al. ). This increase was 369 mainly due to the sesquiterpenes, since total monoterpenoids and norisoprenoids 370 slightly decreased at this stage compared to 15 wpf. This suggests that the late 371 ripening period, rather than the whole post-veraison period, is important for 372 sesquiterpene development at harvest. $\beta$-bourbonene, $\beta$-copaene, guaia-6,9-diene, 373 selina-4(15),6-diene, $\delta$-selinene, $\gamma$-cadinene, 7 -epi- $\alpha$-selinene, and $\alpha$-cadinene first 374 appeared, while $\alpha$-calacorene reappeared, at this stage. The concentration of 375 clovene, $\alpha$-ylangene, $\alpha$-guaiene, rotundone, and calamenene significantly increased, 376 while $\alpha$-humulene, epi-zonarene, and $\delta$-cadinene tended to increase. This was 377 consistent with previous observations in Baga grapes, in which all sesquiterpenes were only observed at later stages of ripening (Coelho, et al., 2006). In another study 379 in Shiraz, higher $\alpha$-ylangene, $\beta$-bourbonene, $\quad$-cadinene, and $\alpha$-humulene concentrations were observed at harvest compared to veraison (May, et al., 2012), although $\alpha$-humulene remained low in the present study. $\alpha$-muurolene was observed in Riesling grapes, but not the current study, at harvest (Kalua, et al., 2010).

\subsection{Terpenoid evolution}

All plant terpenoids are biosynthesised from their universal $\mathrm{C}_{5}$ precursor isopentenyl diphosphate (IPP) (1) and its allylic isomer, dimethylallyl pyrophosphate (DMAPP) (2), via the mevalonate (MVA) and methylerythritol-phosphate (MEP) pathways (Fig. 4a). All terpenes are synthesised by repetitive addition of $\mathrm{C}_{5}$ isoprenoid units, with isoprene (3), the smallest compound in this family. (1) and (2) elongate to form geranyl diphosphate (GPP) (4), while farnesyl diphosphate (FPP) (5) and geranylgeranyl diphosphate (GGPP) (6) are the precursors of monoterpenes $\left(\mathrm{C}_{10}\right)$, 
392

393

394

395

396

397

398

399

400

401

402

403

404

405

406

407

408

409

410

411

sesquiterpenes $\left(C_{15}\right)$, and norisoprenoids $\left(C_{13}\right)$, respectively. We discuss terpenoid biosynthesis in this study according to terpene sub-families and pathways.

\subsubsection{Evolution of monoterpenoids}

The total free monoterpenoid concentration decreased from early berry development onwards (Fig. 3a). The four detected free monoterpenes are biosynthesised via different pathways from (4), while geranyl acetone (7), a monoterpenoid, is mainly derived from $\zeta$-carotene (Not shown in Fig. 4) (Simkin, Schwartz, Auldridge, Taylor, \& Klee, 2004). However, there is still a possibility that (7) could be produced from (5) via nerolidol (8) (Boland, Gäbler, Gilbert, \& Feng, 1998) (Fig. 4b). Geraniol (9), limonene (10), and linalool (11) are synthesised directly from (4) (Davis, 2010; Davis \& Croteau, 2000; Hsiao, et al., 2006; Luan, Mosandl, Münch, \& Wüst, 2005). 1,8cineole (12) is synthesised via the $\alpha$-terpinyl cation (13) and $\alpha$-terpineol (14), while citronellol (15) is synthesised via (9) and mainly exist in S-enantiomer form (Davis, 2010; Davis, et al., 2000; Hsiao, et al., 2006; Luan, et al., 2005). Biosynthesis of the four detected monoterpenes are regulated by different terpenoid synthase genes ( $V v T P S)$, with some overlap (Martin, et al., 2010).

The production of (10) and (12) is similar (Fig. 3a) due to the common VVTPS genes responsible for their biosynthesis. (10) is the product of $V v G w a P h e, V_{v} P N a P i n$, and VvCsbOciM, with the first two genes also responsible for the biosynthesis of (14) and, therefore, related to (12) (Martin, et al., 2010). One $V v P N a P i n$ isoform, $V v P N a P i n 1$, is mainly expressed during flowering, early berry development, and maturity, but not around veraison in Moscato Bianco (Matarese, Cuzzola, Scalabrelli, \& D’Onofrio, 2014). This partially explains the detection of (10) and (12) at wpf 4 in the present 
417 study. Biosynthesis of (14) is also related to another gene, $V v T e r$, which is mainly

418

419

420

421

422

423

424

425

426

427

428

429

expressed at flowering and early berry development in Moscato Bianco (Matarese, et al., 2014), which also explains the relatively higher concentration of (12) at wpf 4.

The production of (9) and (15) is also similar (Fig. 3a), which may due to their biosynthetic relationship (Fig. 4b). (9) is regulated by VvGwGer, VvCSGer, and VVPNGer of the VVTPS-g subfamily of VVTPS, and VVPNGer is likely to be the main enzyme responsible for the biosynthesis of (9) (Martin, et al., 2010; Matarese, Scalabrelli, \& D'Onofrio, 2013). VvPNGer is mainly expressed in flowers and berries in early development (Matarese, et al., 2014), which explains the higher concentration of (9) at wpf 4 . Since (15) is a downstream product of (9), $V v G w G e r$, VvCSGer, and $V v P N G e r$ may also be related to the biosynthesis of (15). In addition, (15) can be produced from (9) and (11) during fermentation (Luan, et al., 2005). (11) is a product of many $V v T P S$ genes including $V v P N a P i n, V v P N R L i n, V v P N L i n N e r$, and VvPNLNGI1 (Martin, et al., 2010), of which VvPNRLin has the highest transcription levels in Moscato Bianco and Aleatico (Matarese, et al., 2013). Absence of (11) in the present study indicates possible differences between floral and nonfloral cultivars in expression of certain gene, and warrants further investigation. The production of (7) is different from the four detected monoterpenes (Fig. 3a), which may be due to its synthesis from $\zeta$-carotene and/or (5) rather than (4). Carotenoid cleavage dioxygenase genes, $\operatorname{LeCCD1A}$ and $\operatorname{LeCCD1B}$, are responsible for the biosynthesis of (7) from $\zeta$-carotene (Simkin, et al., 2004). Overall, the production of (9), (10), (12), and (15) have similar trends of evolution during berry development, which reflects their possible genetic interactions. 
442

443 The total sesquiterpene concentration decreased from early berry development to 444 veraison and slightly increased at harvest. Although present at significantly lower 445

\subsubsection{Sesquiterpene evolution}

\section{veraison and slightly increased at harvest. Although present at significantly lower} total concentrations, the number of sesquiterpenes at wpf 17 was similar to that at wpf 4. However, sesquiterpene profiles at these two stages were different, which may be due to the activation of different biosynthetic pathways at different berry developmental stages. All sesquiterpenes are synthesised from (5) via farnesyl carbocation (16) (Fig. 4). The downstream biosynthetic pathways of the compounds detected in this study can be classified into five categories: the humulyl carbocation pathway (17-20) (Fig. 4c), the germacrene A pathway (21-26) (Fig. 4d), the germacrene C pathway (27-29) (Fig. 4e), the germacrene D pathway (32-54) (Fig. 4f), and the nerolidol diphosphate pathway (55-58) (Fig. 4g) (Bülow \& König, 2000; Chappell \& Coates, 2010; Davis, 2010; Davis, et al., 2000; May, Lange, \& Wüst, 2013)

\subsubsection{The humulyl carbocation pathway}

The humulyl carbocation pathway starts with humulyl carbocation (17), which is derived from (16) (Fig. 4c) (Chappell, et al., 2010; Davis, et al., 2000). The main pathway products include $\beta$-caryophyllene (18), clovene (19), and $\alpha$-humulene (20), which were most abundant at the early stage of berry development (Table 1 in Pangzhen Zhang, et al. ). The biosynthesis of (18) and (20) is regulated by three common VvTPS genes, VvGwECar, VvPNECar, and $V_{v} P N a H u m$, which explains their similar production trends during berry development (Fig. 3a) (Martin, et al., 2010). Previous study have demonstrated that VvGwECar and VvPNaHum are mainly expressed in flower buds and open flowers in Moscato Bianco (Matarese, et 
467 al., 2014). Higher concentrations of (18) and (20) observed at wpf 4 could have been 468 synthesised during flowering, and gradually decrease afterward similar as that of 469 Moscato Bianco (Matarese, et al., 2014). Further study is required to understand the differences between floral and non-floral cultivars in the production of (18) and (19). In addition, (18) is also regulated by a fourth gene, VVPNEb2epi Car, which helps to 472 explain their different production patterns after veraison. The concentration of (19) 473 was extremely low compared to (18) and (20) (Fig. 3a), and the gene responsible for 474 its production has yet to be identified. (19) is only remotely related to (18), and 475 therefore its production pattern is different (Chappell, et al., 2010; Davis, et al., 476 2000).

\subsubsection{The germacrene A pathway}

479 The germacrene A pathway starts with germacrene A (21), which is derived from (16) 480 (Fig. 4d). The primary pathway products include $\alpha$-guaiene (22) and $\alpha$-selinene (23). A very recent study reported aerial oxidation of (22) into rotund-2-ol (24) and rotundone (25) via hydroperoxy-guaiene (26) (Huang, et al., 2014; Huang, Sefton, 483 Sumby, Tiekink, \& Taylor, 2015). It is possible that (22) was released by grape 484 berries and aerially oxidised into (25) (Fig. 4d). However, this chemical synthesis 485 does not explain the storage mechanism of (25). A recent study reported the identification of $V v S T O 2$, which is responsible for the biosynthesis of a cytochrome P450 CYP71BE5 enzyme that oxidize (22) into (25) (Takase, et al., 2015).

489 The production of (25) at different berry developmental stages was further 490 investigated in detail in two growing seasons (Fig. 5). Overall, grapes from the 201249113 growing season contained significantly higher concentrations of (25) $(2.06 \mathrm{ng} / 100$ 
492 berries) compared to those from the 2013-14 growing season (0.90 ng/100 berries), 493 while grapes at harvest (E-L38) had a significantly higher concentration of (25) (3.19 $494 \mathrm{ng} / 100$ berries) than all other groups, followed by $\mathrm{E}-\mathrm{L} 31$ (2.12 ng/100 berries), E-L 32 (1.28 ng/100 berries), E-L 37 (1.10 ng/100 berries), E-L 36 (0.72 ng/100 berries), and E-L 35 (0.44 ng/100 berries) (two-way ANOVA, p<0.05) (Fig. 5a). In the 2012-13 497 growing season, the grape concentration of (25) gradually decreased from pre498 veraison (E-L $31: 3.24 \mathrm{ng} / 100$ berries, $\mathrm{E}-\mathrm{L} 32: 1.52 \mathrm{ng} / 100$ berries) to $80 \%$ veraison 499 (E-L 35: $0.44 \mathrm{ng} / 100$ berries), and then gradually increased until harvest (E-L36: 1.04 ng/100 berries, E-L 37:1.61 ng/100 berries, E-L: 4.48 ng/100 berries) (Fig. 5b). A similar trend was observed in the 2013-14 growing season. The pre-veraison groups (E-L31: 1.00 ng/100 berries, E-L 32: 1.04 ng/100 berries) contained significantly higher concentrations of (25) compared to E-L 35 (0.45ng/100 berries), E-L36 (0.41 ng/100 berries), and E-L 37 (0.59 ng/100 berries). Grapes at harvest (EL 38: $1.89 \mathrm{ng} / 100$ berries) had significantly higher concentrations of $(\mathbf{2 5})$ than all other groups. The concentration of $(25)$ in flower caps were also analysed in the 2013-14 growing season. Flower caps (1.62 ng/100 flowers) contained significantly higher concentrations of rotundone than grape berries at all stages before harvest, and were similar to those in harvested grapes. Previous studies only reported 510 identification of rotundone in grape exocarp at veraison and post-veraison periods 511 (Geffroy, et al., 2014; Takase, et al., 2015). This is the first time rotundone has been reported in flower caps and pre-veraison grape berries.

514 In the present study, (22) and (25) had similar ' $U$ ' shaped production patterns as expected, which further demonstrated our hypothesis that sesquiterpenes from a similar pathway had a similar production pattern. (25) has been converted into a 
517 similar unit when comparing its production pattern with other terpenes compounds in

518 Fig. 3 and Table 1 in Pangzhen Zhang, et al. . A newly discovered allele of VvTPS24 519 encodes the TVGuaS enzyme that is mainly responsible for the production of (22) 520 (Drew, Andersen, Sweetman, Møller, Ford, \& Simonsen, 2015). The timing of 521 TvGuaS production during grape ripening remains unclear, but is likely to be high at 522 early and late berry development stages when (22) was observed (Table 1 in 523 Pangzhen Zhang, et al. ). Previous study reported transcription of VVSTO2 from 8 524 wpf until harvest (18 wpf) with the peak transcription level at $14 \mathrm{wpf}$ (Takase, et al., 525 2015). This explains the fast accumulation of rotundone at post-veraison period 526 observed in the current and previous studies (Fig. 5) (Geffroy, et al., 2014). 527 However, whether the same gene is expressed in flower and pre-veraison grape 528 berries remains unclear, warrants further investigation.

529 Apart from the TvGuaS enzyme encoded by VvTPS24 allele, VvTPS24 could 530 produce the VVPNSelnt enzyme, which is also responsible for the production of (22), 531 but at small percentage (3.5\%) (Martin, et al., 2010). The same enzyme is mainly 532 responsible for the biosynthesis of $\delta$-selinene (27) and 7-epi- $\alpha$-selinene (28), which 533 were only observed at wpf 17 in the current study. This suggested that VvPNSelnt 534 enzyme may only be produced at a late stage of berry development, which was 535 inconsistent to a previous study showing transcription corresponding to VVTPS24 536 mainly at veraison but not at harvest (Sweetman, Wong, Ford, \& Drew, 2012). 537 Therefore, other mechanism/enzymes may exist to regulate the production of (27) 538 and (28).

540 3.3.2.3. The germacrene $C$ pathway 
541 The germacrene C pathway starts with germacrene C (29), which is derived from 542 (16) (Fig. 4e). Major pathway products include guaia-6,9-diene (30) and (27), which 543 had a similar production pattern (Fig. 3b). It is unknown exactly how (28) and (+)544 valencene (31) are synthesised, but they appear to be derived from (16) (Lücker, 545 Bowen, \& Bohlmann, 2004). However, they may be derived from the germacrene A 546 and/or C pathways, since (28) is a product of the same VVPNSelnt enzyme as (22) 547 and (27) (Martin, et al., 2010). It has previously been shown that VitisM4670 cDNA 548 expression is mainly confined to late-stage berry development, and encodes the $549 V v V a l$ VVTPS responsible for the biosynthesis of (28) and (31) (Lücker, et al., 2004). 550 This is consistent with our finding that (28) is only present at wpf 17 . In addition, (31) 551 could be further oxidized into $\beta$-nootkatol by the same cytochrome P450 enzyme that 552 turns (22) into (25) (Takase, et al., 2015).

554 3.3.2.4. The germacrene $D$ pathway

555 The germacrene D pathway is the most complicated pathway implicated in the 556 synthesis of the products detected in the present study, and is thought to be a major 557 sesquiterpene synthesis pathway (Fig. 4f) (Bülow, et al., 2000; Chappell, et al., 2010; 558 Davis, et al., 2000). Germacrene D (32) only presents in (R)-enantiomer form in 559 grape berries and is mainly regulated by $V v G w G e r D$ and $V v P N G e r D$ and is also a 560 by-product of VvGwECar and VvPNECar (Martin, et al., 2010; May, et al., 2013). 561 Three major sub-pathways could explain our current findings: the cadinenyl cation 562 pathway (33-36), the muurolenyl cation pathway (37-49), and the amophenyl cation 563 pathway (50-51). 
565 The cadinenyl cation pathway starts with the cadinenyl cation (33), which is derived 566 from (32) (Bülow, et al., 2000; Chappell, et al., 2010; Davis, et al., 2000). Its major 567 products are $\gamma$-cadinene (34) and $\alpha$-cadinene (35), both of which were only observed 568 at wpf 17 (Table 1 in Pangzhen Zhang, et al. ). (34) is a major product of $V v G w g C a d$ 569 and a minor product of VvPNCuCad (Martin, et al., 2010). It is uncertain how (35) is 570 synthesised. $\omega$-cadinene (36) may also be derived from (35) (Bülow, et al., 2000). In 571 the present study, (36) showed a different pattern of production during berry 572 development compared to (34) and (35) (Fig. 3b). Therefore, the pathway converting 573 (35) to (36) might not be activated at the berry development stages studied, and the 574 latter may be produced via an alternative pathway, as discussed below.

576 The muurolenyl cation pathway is important to discuss in the context of the present 577 study, and starts with the muurolenyl cation (37), derived from (32) (Bülow, et al., 578 2000; Chappell, et al., 2010; Davis, et al., 2000). The direct products of (37) are $\alpha$ 579 muurolene (38), $\delta$-cadinene (39), $\gamma$-muurolene (40), and $\alpha$-copaene (41). $\alpha$ 580 calacorene (42), (36), and cis-muurola-4(15),5-diene (43) are synthesised directly 581 from (39). Two intermediates (A: 44 and B: 45) are also synthesised from (39), then converted into epi-zonarene (46) and zonarene (47), respectively. (46) and (47) can be further converted into different calamenenes $((R): 48,(S): 49)$, which can also be synthesised from (43). In the present study, (43) was not detected at any developmental stages, indicating that the pathway between $(\mathbf{4 3})$ and $(48,49)$ may 586 not be activated in Shiraz grapes at the berry developmental stages studied.

588 The majority of sesquiterpenes produced by the muurolenyl cation pathway had 589 highly similar production patterns (Fig. 3a) and were predominantly produced at early 
590 berry developmental stages before veraison (wpf 4-11). The production pattern of 591 (39) was similar to (47) pre-veraison, and to (46) from wpf 15 to 17(Fig. 3a),

592

593

594

595

596

597

598

599

600

601

602

603

604

605

606

607

608

609

610

611

612

613

614

suggesting that major downstream product of (39) could switch from (47) to (46) after veraison. (48) and (49) are downstream products of (46) and (47), respectively. The $(48,49)$ observed in this study is more like to be (49) before veraison and (48) postveraison. Other sesquiterpenes from muurolenyl cation pathway, (36), (38), (40), and (42) had similar production patterns, and were only observed pre-veraison(Fig. b). The $V_{v} P N C u C a d$ gene product is responsible for the production of (39) and (41), but no other enzymes have been identified as responsible for the production of sesquiterpenes from the muurolenyl cation pathway (Martin, et al., 2010).

The amophenyl cation pathway starts with the amophenyl cation (50) and is mainly responsible for the biosynthesis of $\alpha$-amorphene, $\gamma$-amorphene, $\delta$ - amorphene, and w-amorphene (Bülow, et al., 2000). However, none of these compounds were detected in the present study, the only product detected being $\alpha$-ylangene (51). In addition, the VVTPS gene responsible for amophenyl cation production remains elusive.

Apart from the cadinenyl cation, muurolenyl cation, and amophenyl cation subpathways, the germacrene D pathway is also responsible for the biosynthesis of (27), selina-4(15),6-diene (52), $\beta$-bourbonene (53), and $\beta$-copaene (54) (Bülow, et al., 2000); these compounds were only observed at harvest in the present study (Table 1 in Pangzhen Zhang, et al. ). (52) can be further modified into (27), which is also a product of the germacrene C pathway, as discussed earlier. Therefore, it is unclear which pathway produces (27). 
616 Previous studies have reported that the VVTPS gene responsible for the production

617 of (32), $V v G w G e r D$, is highly expressed in flowers but has low expression in grape 618 berries (Matarese, et al., 2014). However, no (32) was observed in this study. (32) 619 might have already been converted to downstream products, such as those in the 620 muurolenyl cation pathway, after flowering. It is also reasonable to conclude that the 621 cadinenyl cation and amophenyl cation pathways are regulated by different VVTPS 622 genes than the muurolenyl cation pathway, since their end-product production patterns were completely different during berry development (Fig. 3).

624

\subsubsection{The nerolidol diphosphate pathway}

The nerolidol diphosphate pathway significantly overlaps with the germacrene D pathway (Fig. 4g). (37), (51), and (54) may be synthesised from (16) through the nerolidol diphosphate pathway via nerolidol diphosphate (NPP)

(55) and 629 intermediate C (56), rather than from the germacrene D pathway (Chappell, et al., 2010; Davis, et al., 2000). Since (37) was the precursor for the muurolenyl cation pathway, the whole pathway may not necessarily be derived from the germacrene D pathway but from the nerolidol diphosphate pathway (56). Furthermore, the starting point of the germacrene D pathway, (32), may derive from (56) (i.e., the nerolidol diphosphate pathway) (Chappell, et al., 2010; Davis, et al., 2000). 1-epi-cubenol (57) 635 is another nerolidol diphosphate pathway product via intermediate D (58). This 636 compound and its isomer, cubenol, had similar production patterns (Fig. 3b), and 637 their biosynthesis may, therefore, likely be related. (57) was only observed at wpf 4 , 638 which was consistent with timing of production of most compounds derived from the 639 muurolenyl cation pathway (37-49). Since both (57) and muurolenyl cation pathway 
640 sesquiterpenes were mainly detected at wpf 4 , it would be reasonable to assume 641 that (56) was abundant at the same time. At wpf 4, the whole muurolenyl cation 642 pathway (37-49) was likely produced from (56) instead of (32), which could explain 643 the absence of $(27),(34),(35),(51),(52),(53)$ and (54) at wpf 4 . This also suggests 644 that the pathway between (56) and (32) may not be activated at wpf 4. (51) and (54) 645 were only observed at late stages of berry development, and therefore the pathway 646 producing (51) and (54) from (56) might not be activated at wpf 4 . In addition, the 647 germacrene D pathway (32-54) derived from (16), except muurolenyl cation sub648 pathway (37-49), may only be activated near harvest to produce (27), (34), (35), 649 (51), (52), (53) and (54).

\subsubsection{Norisoprenoid evolution}

652 The total norisoprenoid concentration reached a maximum at wpf 6 and decreased 653 thereafter until wpf 17. All norisoprenoids detected in the present study are 654 synthesised from (6) via $\beta$-carotene (59) (Fig. 4h) (Mendes-Pinto, 2009). 655 Theaspirane (60) and $\beta$-ionone (61) are derived from (59) via different pathways, 656 while $\beta$-damascenone (62) is derived from (59) via neoxanthin (63) (Baumes, Wirth, 657 Bureau, Gunata, \& Razungles, 2002; Mendes-Pinto, 2009). In grape berries, the 658 genes encoding carotenoid biosynthesis and catabolism are skin-specific (Grimplet, 659 et al., 2007). Previous studies found that carotenoids were mainly synthesised pre660 veraison and degraded after veraison to produce norisoprenoids (Grimplet, et al., 661 2007). However, the norisoprenoids formed from carotenoids are mainly in 662 glycoconjugated forms (Wirth, Guo, Baumes, \& Günata, 2001). Another study 663 reported that the concentration of total glycoconjugated norisoprenoids gradually 664 increases from veraison to harvest in Shiraz, with no free norisoprenoids produced at 
665 any point (Mathieu, Terrier, Procureur, Bigey, \& Günata, 2005). Clearly, the free 666 norisoprenoids observed in the present study reached maximum level before 667 veraison, and no significant increase in free norisoprenoids was observed after wpf 668 11. This suggests that, even if glycoconjugated norisoprenoids were produced after 669 veraison, the glycosidase enzyme may not be available in Shiraz to release free 670 norisoprenoids during post-veraison stages (Mathieu, et al., 2005). In addition, 671 abscisic acid (64), a sesquiterpene, can be biosynthesised from (63) rather than (5) 672 (Taylor, Burbidge, \& Thompson, 2000). It is well known that biosynthesis of this 673 compound is related to plant water availability (Christmann, Moes, Himmelbach, 674 Yang, Tang, \& Grill, 2006). A recent study reported that the biosynthesis of (25) was 675 closely related to vineyard water availability (Geffroy, et al., 2014; Pangzhen Zhang, 676 et al., 2015). Therefore, the biosynthesis of (64) may be used as an indicator of (25).

\section{4. Conclusions}

679 Monoterpenoids, sesquiterpenes, and norisoprenoids have different production 680 patterns during berry development from pea-size to commercial harvest. Clear 681 differences in berry terpene profiles at different berry developmental stages indicate 682 that the mechanisms of terpene biosynthesis may be different at different ripening 683 stages. The decrease in the number and concentration of terpenes from pre684 veraison to veraison suggests that a number of their biosynthetic pathways could be 685 inactivated. Alternatively, terpenes produced during early berry development may be 686 degraded into other compounds or converted into non-volatile forms. Sharp increases in sesquiterpene concentrations during the last two weeks of berry 688 development indicate that the later ripening stages, rather than whole veraison to 
689 maturity period, is more critical in defining the final concentration of sesquiterpenes, 690 such as rotundone, in harvested grapes and, therefore, wine.

691

692 Our analysis of terpene compound evolution during berry development suggests that 693 terpene biosynthesis is more dependent on the activation of the pathway it belongs 694 to, and terpenes synthesised via similar pathways tend to appear at similar berry 695 developmental stages. Categorisation of terpenes based on their biosynthetic 696 pathway, especially sesquiterpenes, helps to understand pathway activation and 697 regulation and can be used to predict the production patterns for other, less wellcharacterised compounds in the same pathway. Furthermore, highly similar production patterns in the same pathway will help future molecular classification studies that investigate the genes that regulate the whole pathway rather than a single product, and more pathway interactions are likely to be present. Even though some compounds can be synthesised by multiple pathways, not all pathways are active simultaneously. 


\section{Acknowledgements}

705 This work was sponsored by the Rathbone Wine Group, the University of Melbourne, 706 the Australian Wine Research Institute (AWRI), and the Australia Grape and Wine 707 Authority. The work was performed at the University of Melbourne and AWRI and 708 was supported by Australia's grape growers and winemakers through their 709 investment body, the Australia Grape and Wine Authority, with matched funds from 710 the Australian Government and partial funding from the Faculty of Veterinary and

711 Agricultural Science at the University of Melbourne. This publication has been

712 written with the support of the AgreenSkills fellowship programme to Kate

713 Howell who has received funding from the EU's Seventh Framework

714 Programme under grant agreement $N^{O}$ FP7-609398. The authors thank

715 Sheridan Barter (AWRI) for providing the protocols and training in analysis of 716 monoterpenoids, sesquiterpenes and norisoprenoids and their excellent technical 717 assistance in rotundone analysis and Damien Sheehan (Rathbone Wine Group) for 718 his support and assistance with the field trials. 
719

720

721

722

723

724

725

726

727

728

729

730

731

732

733

734

735

736

737

738

739

740

741

742

743

744

745

746

747

748

749

750

751

752

753

754

755

756

757

758

759

760

761

762

763

764

765

766

\section{References}

Baumes, R., Wirth, J., Bureau, S., Gunata, Y., \& Razungles, A. (2002). Biogeneration of C13norisoprenoid compounds: experiments supportive for an apo-carotenoid pathway in grapevines. Analytica Chimica Acta, 458(1), 3-14.

Boland, W., Gäbler, A., Gilbert, M., \& Feng, Z. (1998). Biosynthesis of C11 and C16 homoterpenes in higher plants; stereochemistry of the C - C-bond cleavage reaction. Tetrahedron, 54(49), 14725-14736.

Bülow, N., \& König, W. A. (2000). The role of germacrene D as a precursor in sesquiterpene biosynthesis: investigations of acid catalyzed, photochemically and thermally induced rearrangements. Phytochemistry, 55(2), 141-168.

Chappell, J., \& Coates, R. M. (2010). Sesquiterpenes. In L. Mander \& H.-W. Liu (Eds.), Comprehensive Natrual Products II, vol. 1 (pp. 609-641). Kidlington, United Kingdom: Elsevier L.td.

Christmann, A., Moes, D., Himmelbach, A., Yang, Y., Tang, Y., \& Grill, E. (2006). Integration of Abscisic Acid Signalling into Plant Responses. Plant Biology, 8(3), 314-325.

Coelho, E., Rocha, S. M., Barros, A. S., Delgadillo, I., \& Coimbra, M. A. (2007). Screening of varietyand pre-fermentation-related volatile compounds during ripening of white grapes to define their evolution profile. Analytica Chimica Acta, 597(2), 257-264.

Coelho, E., Rocha, S. M., Delgadillo, I., \& Coimbra, M. A. (2006). Headspace-SPME applied to varietal volatile components evolution during Vitis vinifera L. cv. 'Baga' ripening. Analytica Chimica Acta, 563(1-2), 204-214.

Coombe, B. G., \& Iland, P. G. (2004). Grape berry development and winegrape quality. In P. R. Dry \& B. G. Coombe (Eds.), Viticulture 2nd ed., vol. 1 (pp. 210-248). Adelaide: Winetitles.

Davis, E. M. (2010). Advances in the Enzymology of Monoterpenoid Cyclization Reactions. In L. Mander \& H.-W. Liu (Eds.), Comprehensive Natrual Products II, vol. 1 (pp. 585-608). Kidlington, United Kingdom: Elsevier L.td.

Davis, E. M., \& Croteau, R. (2000). Cyclization enzymes in the biosynthesis of monoterpenes, sesquiterpenes, and diterpenes. In Biosynthesis, (pp. 53-95). Berlin Heidelberg: Springer.

Drew, D. P., Andersen, T. B., Sweetman, C., Møller, B. L., Ford, C., \& Simonsen, H. T. (2015). Two key polymorphisms in a newly discovered allele of the Vitis vinifera TPS24 gene are responsible for the production of the rotundone precursor $\alpha$-guaiene. Journal of Experimental Botany, erv491.

Dunlevy, J. D., Kalua, C. M., Keyzers, R. A., \& Boss, P. K. (2009). The Production of Flavour \& Aroma Compounds in Grape Berries. In K. Roubelakis-Angelakis (Ed.), Grapevine Molecular Physiology \& Biotechnology 2 ed., (pp. 293-340): Springer Netherlands.

Fang, Y., \& Qian, M. C. (2006). Quantification of Selected Aroma-Active Compounds in Pinot Noir Wines from Different Grape Maturities. Journal of Agricultural and Food Chemistry, 54(22), 8567-8573.

García, E., Chacón, J. L., Martínez, J., \& Izquierdo, P. M. (2003). Changes in Volatile Compounds during Ripening in Grapes of Airén, Macabeo and Chardonnay White Varieties Grown in La Mancha Region (Spain). Food Science and Technology International, 9(1), 33-41.

Geffroy, O., Dufourcq, T., Carcenac, D., Siebert, T., Herderich, M., \& Serrano, E. (2014). Effect of ripeness and viticultural techniques on the rotundone concentration in red wine made from Vitis vinifera L. Cv. Duras. Australian Journal of Grape and Wine Research, 20(3), 401-408.

Gladstones, J. S. (2004). Climate and Australian Viticulture. In P. R. Dry \& B. G. Coombe (Eds.), Viticulture 2nd ed., vol. 1 (pp. 90-118). Adelaide: Winetitles.

Grimplet, J., Deluc, L. G., Tillett, R. L., Wheatley, M. D., Schlauch, K. A., Cramer, G. R., \& Cushman, J. C. (2007). Tissue-specific mRNA expression profiling in grape berry tissues. BMC Genomics, 8 , 187-123. 
Herderich, M. J., Siebert, T. E., Parker, M., Capone, D. L., Jeffery, D. W., Osidacz, P., \& Francis, I. L. (2012). Spice Up Your Life: Analysis of Key Aroma Compounds in Shiraz. In Flavor Chemistry of Wine and Other Alcoholic Beverages, vol. 1104 (pp. 3-13): American Chemical Society.

Hjelmeland, A. K., \& Ebeler, S. E. (2015). Glycosidically Bound Volatile Aroma Compounds in Grapes and Wine: A Review. American Journal of Enology and Viticulture, 66(1), 1-11.

Hsiao, Y. Y., Tsai, W. C., Kuoh, C. S., Huang, T. H., Wang, H. C., Wu, T. S., Leu, Y. L., Chen, W. H., \& Chen, H. H. (2006). Comparison of transcripts in Phalaenopsis bellina and Phalaenopsis equestris (Orchidaceae) flowers to deduce monoterpene biosynthesis pathway. BMC Plant Biol, 6, 14.

Huang, A.-C., Burrett, S., Sefton, M. A., \& Taylor, D. K. (2014). Production of the Pepper Aroma Compound, (-)-Rotundone, by Aerial Oxidation of $\alpha$-Guaiene. Journal of Agricultural and Food Chemistry, 62(44), 10809-10815.

Huang, A.-C., Sefton, M. A., Sumby, C. J., Tiekink, E. R. T., \& Taylor, D. K. (2015). Mechanistic Studies on the Autoxidation of $\alpha$-Guaiene: Structural Diversity of the Sesquiterpenoid Downstream Products. Journal of Natural Products, 78(1), 131-145.

Iland, P. (2004). Chemical analysis of grapes and wine : techniques and concepts. Campbelltown, SA: Patrick lland Wine Promotions.

Kalua, C. M., \& Boss, P. K. (2009). Evolution of Volatile Compounds during the Development of Cabernet Sauvignon Grapes (Vitis vinifera L.). Journal of Agricultural and Food Chemistry, 57(9), 3818-3830.

Kalua, C. M., \& Boss, P. K. (2010). Comparison of major volatile compounds from Riesling and Cabernet Sauvignon grapes (Vitis vinifera L.) from fruitset to harvest. Australian Journal of Grape and Wine Research, 16(2), 337-348.

Luan, F., Mosandl, A., Münch, A., \& Wüst, M. (2005). Metabolism of geraniol in grape berry mesocarp of Vitis vinifera L. cv. Scheurebe: demonstration of stereoselective reduction, E/Zisomerization, oxidation and glycosylation. Phytochemistry, 66(3), 295-303.

Lücker, J., Bowen, P., \& Bohlmann, J. (2004). Vitis vinifera terpenoid cyclases: functional identification of two sesquiterpene synthase cDNAs encoding (+)-valencene synthase and $(-)$-germacrene $D$ synthase and expression of mono- and sesquiterpene synthases in grapevine flowers and berries. Phytochemistry, 65(19), 2649-2659.

Martin, D. M., Aubourg, S., Schouwey, M. B., Daviet, L., Schalk, M., Omid, T., Lund, S. T., \& Bohlmann, J. (2010). Functional Annotation, Genome Organization and Phylogeny of the Grapevine (Vitis vinifera) Terpene Synthase Gene Family Based on Genome Assembly, FLcDNA Cloning, and Enzyme Assays. BMC Plant Biology, 10, 226-247.

Matarese, F., Cuzzola, A., Scalabrelli, G., \& D'Onofrio, C. (2014). Expression of terpene synthase genes associated with the formation of volatiles in different organs of Vitis vinifera. Phytochemistry, 105(0), 12-24.

Matarese, F., Scalabrelli, G., \& D'Onofrio, C. (2013). Analysis of the expression of terpene synthase genes in relation to aroma content in two aromatic Vitis vinifera varieties. Functional Plant Biology, 40(6), 552-565.

Mathieu, S., Terrier, N., Procureur, J., Bigey, F., \& Günata, Z. (2005). A Carotenoid Cleavage Dioxygenase from Vitis vinifera L.: functional characterization and expression during grape berry development in relation to C13-norisoprenoid accumulation. Journal of Experimental Botany, 56(420), 2721-2731.

May, B., Lange, B. M., \& Wüst, M. (2013). Biosynthesis of sesquiterpenes in grape berry exocarp of Vitis vinifera L.: Evidence for a transport of farnesyl diphosphate precursors from plastids to the cytosol. Phytochemistry, 95(0), 135-144.

May, B., \& Wüst, M. (2012). Temporal development of sesquiterpene hydrocarbon profiles of different grape varieties during ripening. Flavour and Fragrance Journal, 27(4), 280-285.

Mendes-Pinto, M. M. (2009). Carotenoid breakdown products the-norisoprenoids-in wine aroma. Archives of Biochemistry and Biophysics, 483(2), 236-245. 
Parker, M., Pollnitz, A. P., Cozzolino, D., Francis, I. L., \& Herderich, M. J. (2007). Identification and Quantification of a Marker Compound for 'Pepper' Aroma and Flavor in Shiraz Grape Berries by Combination of Chemometrics and Gas Chromatography-Mass Spectrometry. Journal of Agricultural and Food Chemistry, 55(15), 5948-5955.

Pearce, I., \& Coombe, B. G. (2004). Grapevine phenology. In P. R. Dry \& B. G. Coombe (Eds.), Viticulture 2nd ed., vol. 1 (pp. 210-248). Adelaide: Winetitles.

Siebert, T. E., Wood, C., Elsey, G. M., \& Pollnitz, A. P. (2008). Determination of Rotundone, the Pepper Aroma Impact Compound, in Grapes and Wine. Journal of Agricultural and Food Chemistry, 56(10), 3745-3748.

Simkin, A. J., Schwartz, S. H., Auldridge, M., Taylor, M. G., \& Klee, H. J. (2004). The tomato carotenoid cleavage dioxygenase 1 genes contribute to the formation of the flavor volatiles $\beta$-ionone, pseudoionone, and geranylacetone. The Plant Journal, 40(6), 882-892.

Sweetman, C., Wong, D. C., Ford, C. M., \& Drew, D. P. (2012). Transcriptome analysis at four developmental stages of grape berry (Vitis vinifera cv. Shiraz) provides insights into regulated and coordinated gene expression. BMC Genomics, 13(1), 691.

Takase, H., Sasaki, K., Shinmori, H., Shinohara, A., Mochizuki, C., Kobayashi, H., Ikoma, G., Saito, H., Matsuo, H., \& Suzuki, S. (2015). Cytochrome P450 CYP71BE5 in grapevine (Vitis vinifera) catalyzes the formation of the spicy aroma compound (-)-rotundone. Journal of Experimental Botany, erv496.

Taylor, I. B., Burbidge, A., \& Thompson, A. J. (2000). Control of abscisic acid synthesis. Journal of Experimental Botany, 51(350), 1563-1574.

Wirth, J., Guo, W., Baumes, R., \& Günata, Z. (2001). Volatile Compounds Released by Enzymatic Hydrolysis of Glycoconjugates of Leaves and Grape Berries from Vitis vinifera Muscat of Alexandria and Shiraz Cultivars. Journal of Agricultural and Food Chemistry, 49(6), 29172923.

Wood, C., Siebert, T. E., Parker, M., Capone, D. L., Elsey, G. M., Pollnitz, A. P., Eggers, M., Meier, M., Vössing, T., Widder, S., Krammer, G., Sefton, M. A., \& Herderich, M. J. (2008). From Wine to Pepper: Rotundone, an Obscure Sesquiterpene, Is a Potent Spicy Aroma Compound. Journal of Agricultural and Food Chemistry, 56(10), 3738-3744.

Zhang, P., Barlow, S., Krstic, M., Herderich, M., Fuentes, S., \& Howell, K. (2015). Within-Vineyard, Within-Vine, and Within-Bunch Variability of the Rotundone Concentration in Berries of Vitis vinifera L. cv. Shiraz. Journal of Agricultural and Food Chemistry, 63(17), 4276-4283.

Zhang, P., Fuentes, S., Siebert, T., Krstic, M., Herderich, M., Barlow, E. W. R., \& Howell, K. Terpene production pattern during the development of Vitis vinifera L. Cv. Shiraz grapes. Data in Brief, submitted.

Zhang, P., Howell, K., Krstic, M., Herderich, M., Barlow, E. W. R., \& Fuentes, S. (2015). Environmental Factors and Seasonality Affect the Concentration of Rotundone in Vitis vinifera L. cv. Shiraz Wine. PLOS ONE, 10(7), e0133137. 


\section{$858 \quad$ Figure legends}

859 Fig. 1. Chromatograms showing the differences in terpenoids at different berry development stages: 860 (a) pre-veraison, 4 weeks post flowering, E-L 31; (b) 80\% veraison, 11 weeks post flowering, E-L 35861 36; (c) post-veraison, 17 weeks post flowering, E-L 38. Peaks: (1) Limonene; (2) 1,8-Cineole; (3) 862 Geraniol; (4) Theaspirane isomer A; (5) Theaspirane isomer B; (6) Clovene; (7) $\alpha$-Ylangene; (8) $\alpha$ 863 copaene (internal standard); (9) (E)- $\beta$-Damascenone; (10) $\beta$-Bourbonene; (11) (E)- $\beta$-Caryophyllene; 864 (12) $\beta$-Copaene; (13) $\alpha$-Guaiene; (14) Guaia-6,9-diene; (15) Selina-4(15),6-diene; (16) Geranyl 865 acetone; (17) $\alpha$-Humulene; (18) Y-Muurolene; (19) $\beta$-Ionone; (20) $\delta$-Selinene; (21) epi-Zonarene; (22) $866 \alpha$-Muurolene; (23) Y-Cadinene; (24) $\delta$-Cadinene; (25) Cis/trans-Calamenene; (26) Zonarene; (27) 867 Citronellol; (28) 7-epi- $\alpha$-Selinene; (29) $\omega$-Cadinene; (30) $\alpha$-Cadinene; (31) $\alpha$-Calacorene; (32) 1-epi868 Cubenol; (33) Cubenol

Fig. 2. Discriminant analysis biplots illustrating the pattern of terpenoids production at different berry 871 development stages in Shiraz grapes. Numbers in the biplots represent the weeks post-flowering 872 (wpf) for Shiraz grapes in the 2013-14 growing season.

873

874 Fig. 3. Heat map of terpenoids compounds in grape berries at different grape development stages in 875 the 2013-14 growing season, and heat map legends show the relative concentration range of (a) all terpenoids detected and (b) selected sesquiterpenes. Number in front of each compound represents

877 the compound number in the Fig. 4. The Biosynthesis of cubenol is unclear, therefore number was not assigned to this compound.

Fig. 4. Biosynthesis of selected monoterpenoids, sesquiterpenes and norisoprenoids. Arrow line 881 indicates the biosynthesis pathways, while the biosynthesis pathways labelled by dash line may not 882 be activated in the present study. " $1 \times, 2 \times, 3 \times$ " represent the unit of isopentenyl diphosphate (IPP) to synthesis different compounds. Compounds detected in this study are enclosed in red boxes. represent all variations of a particular compound. 
887 Fig. 5. Comparison of grape berry rotundone concentration ( $\mathrm{ng} / 100$ berries) at different phenological 888 stages of ripening in the 2012-13 and 2013-14 growing seasons. (a) Two-way ANOVA $(p<0.05)$ was 889 conducted to compare grape rotundone concentration among ripening stages and between two 890 growing seasons. (b) One-way ANOVA $(p<0.05)$ was conducted to compare grape rotundone 891 concentration among different ripening stages in each growing seasons separately. a, b, c, d were 892 used to label significant differences $(p<0.05)$ among ripening stages; $A, B$ were used to label 893 significant differences $(p<0.05)$ between growing seasons; $\alpha, \beta$ were used to label significant 894 differences $(p<0.05)$ in rotundone among flower and grape berries of different ripening stages in the 895 2013-14 growing season.

896 


\section{Table legend}

898 Table 1. Sampling details and grape composition at different phenological stages of grape ripening ${ }^{a}$ 899

900

901 


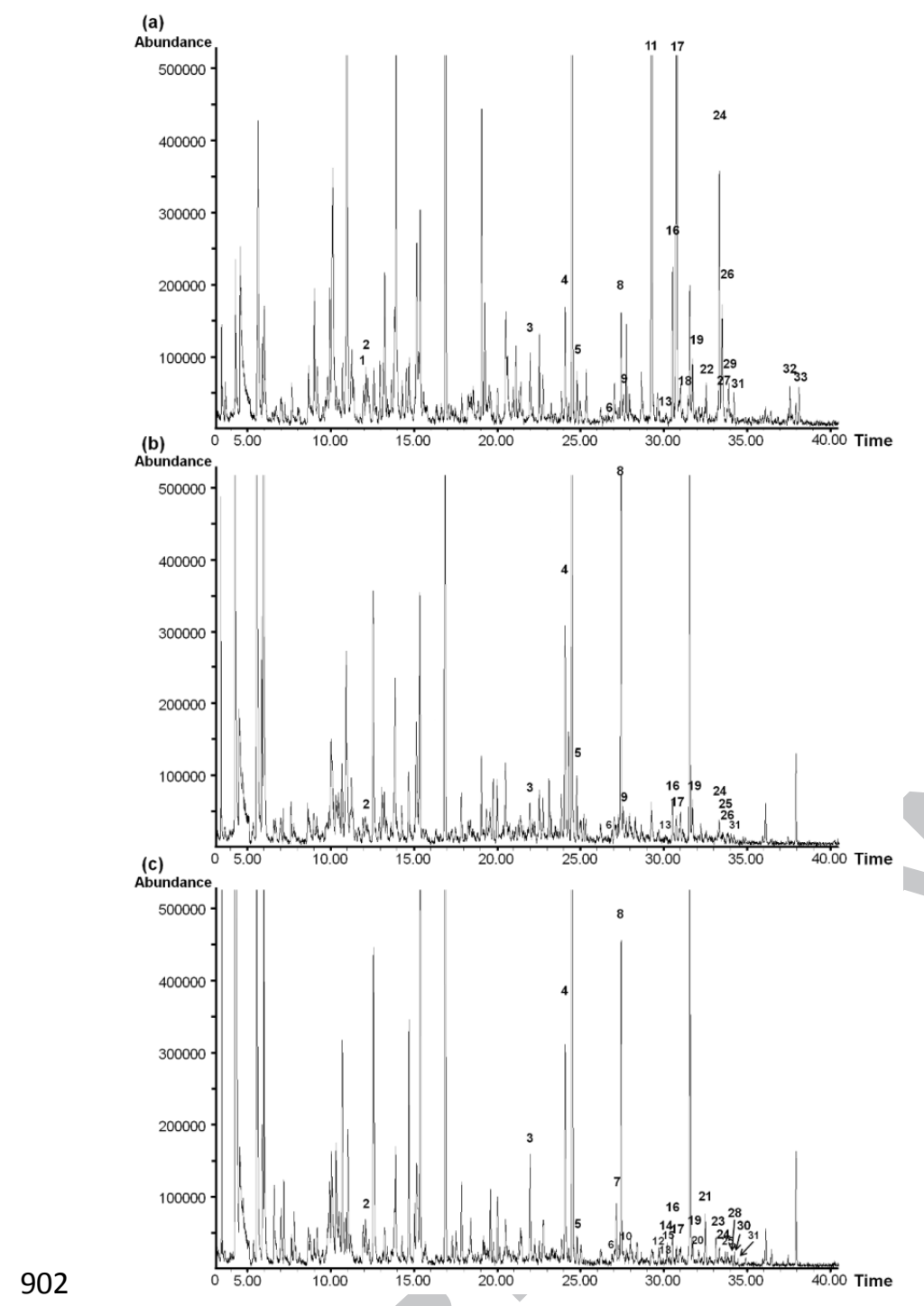

903

Fig. 1. 


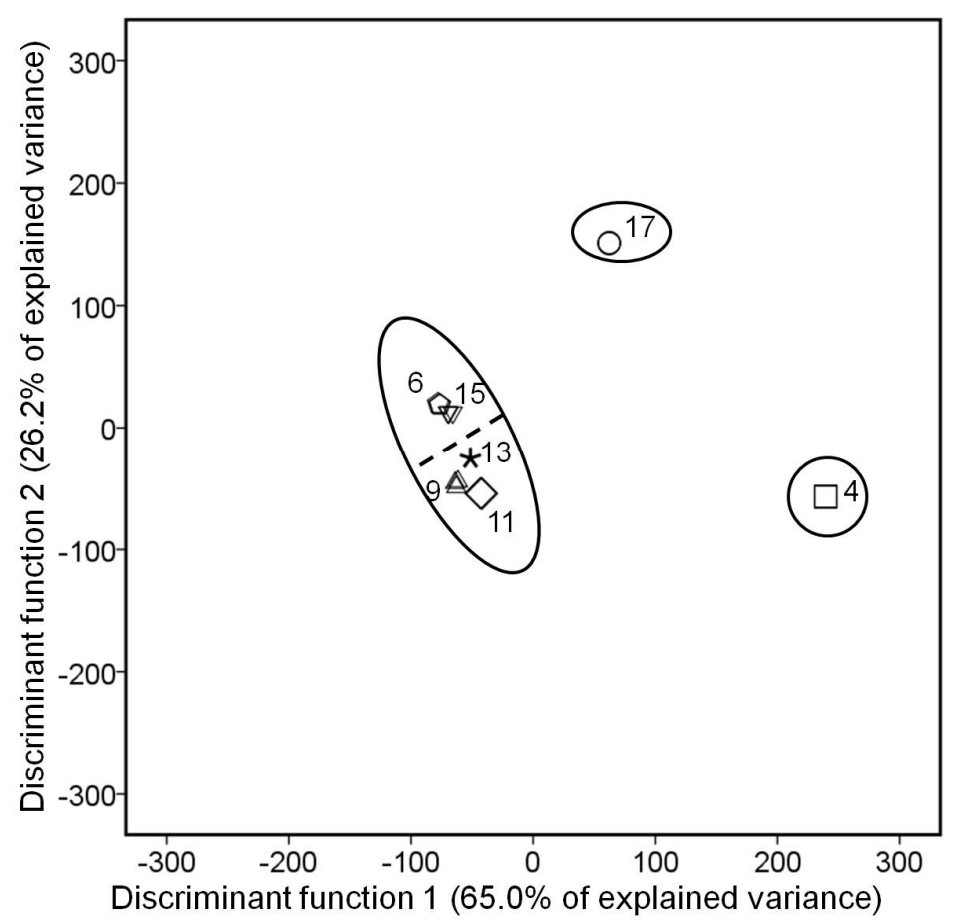

904

905

Fig. 2.

906 


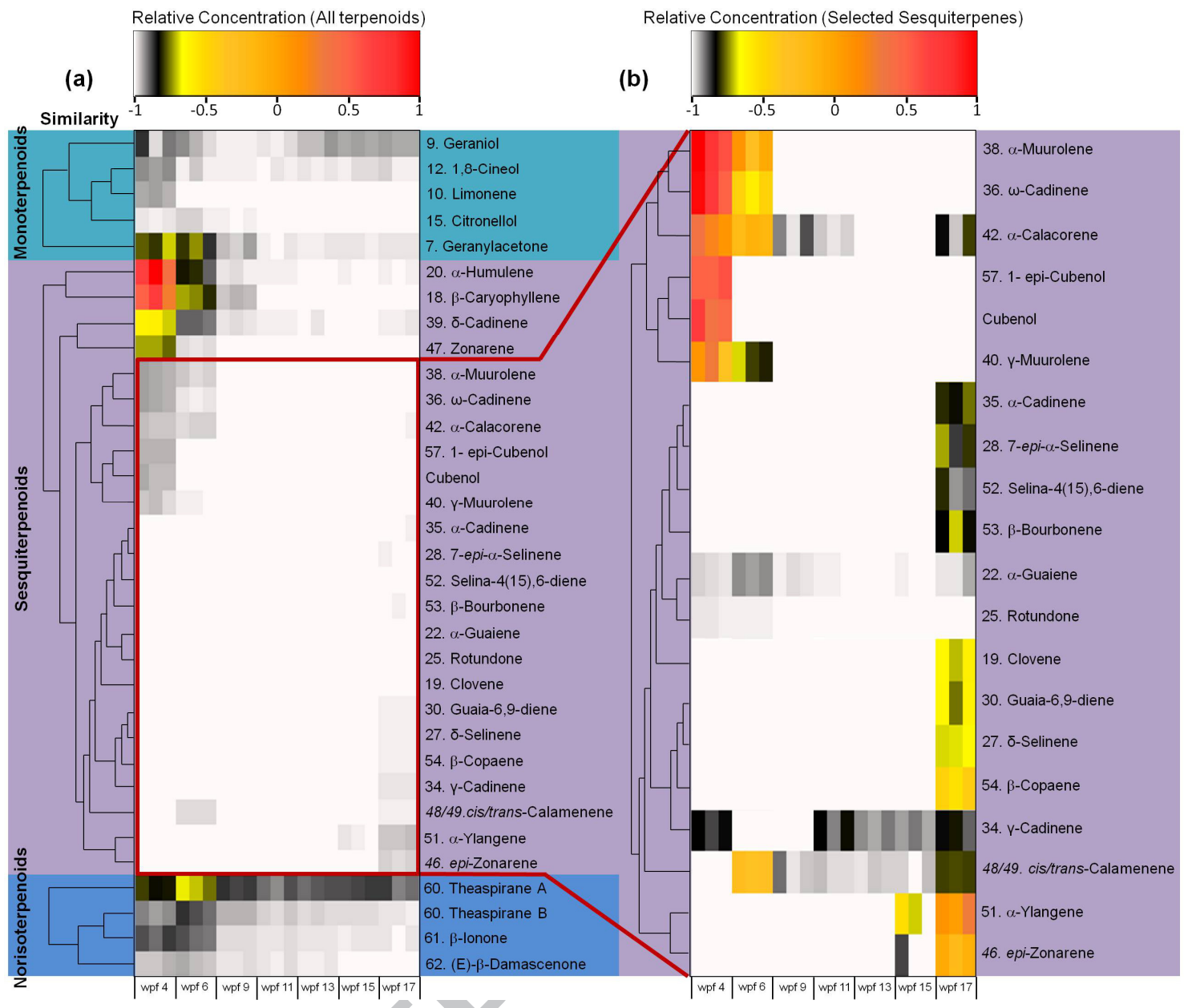

Fig. 3. 


\section{ACCEPTED MANUSCRIPT}
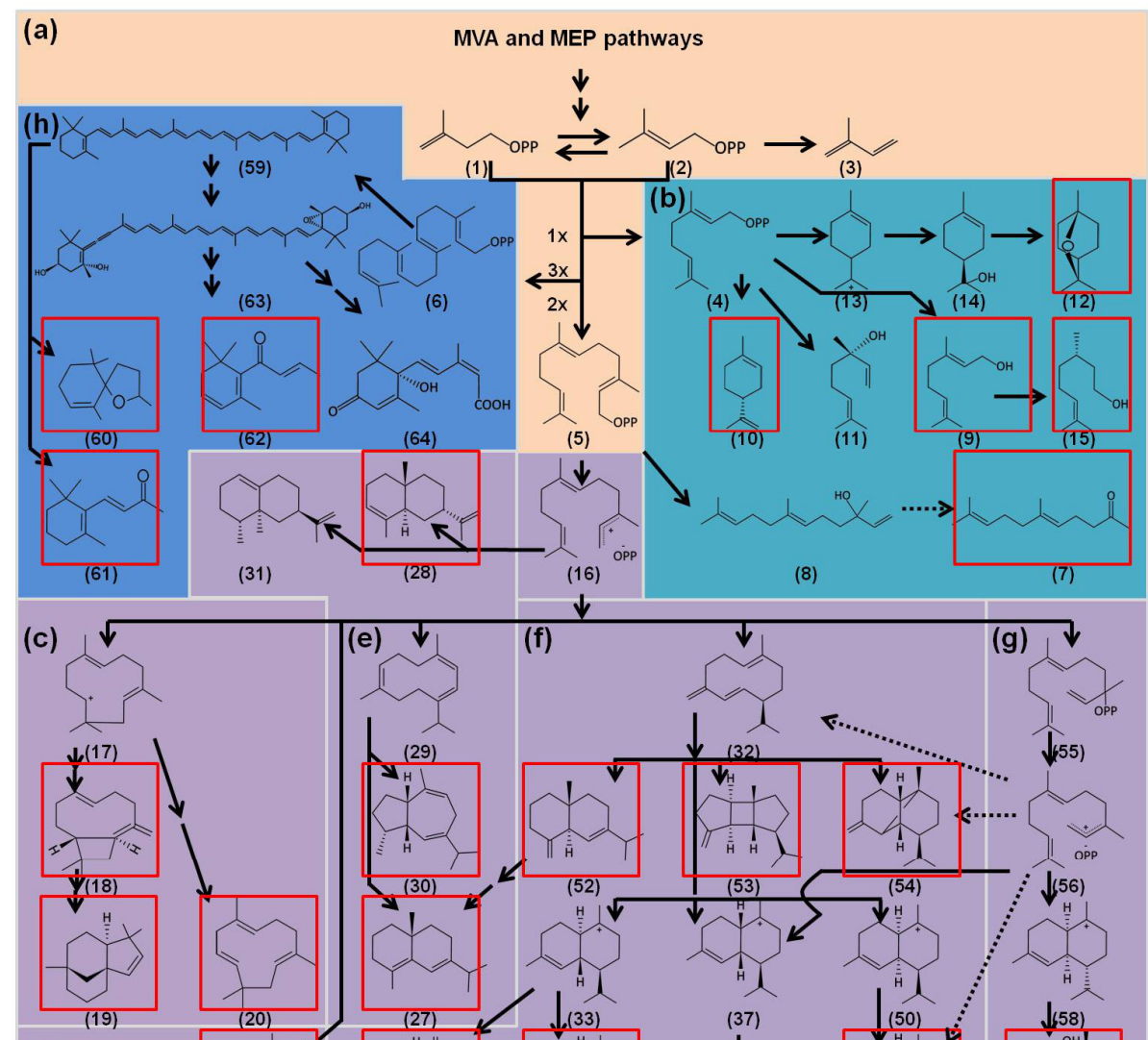

(d)
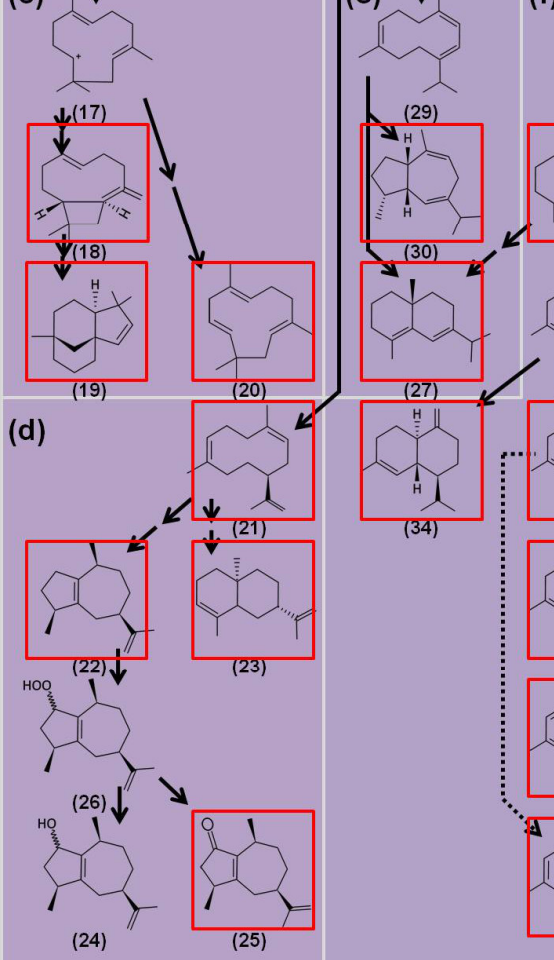

$\downarrow$
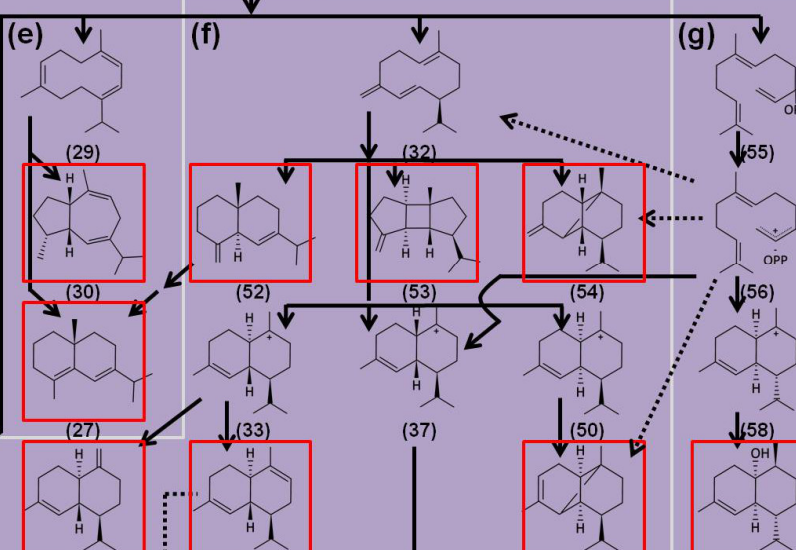
(a)

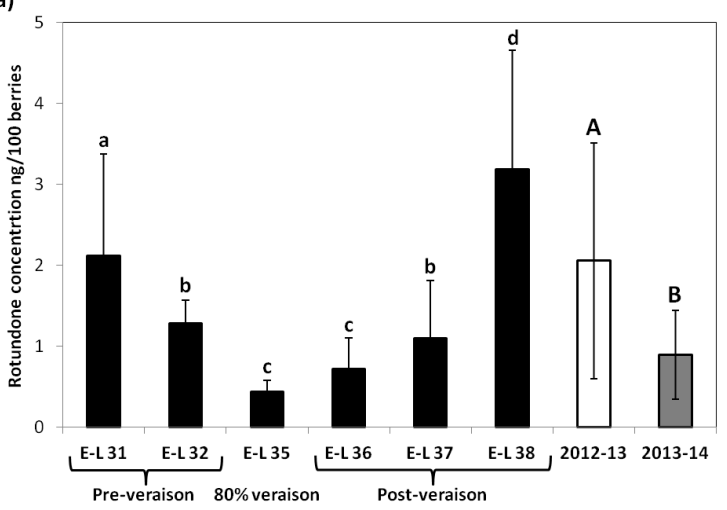

(b)

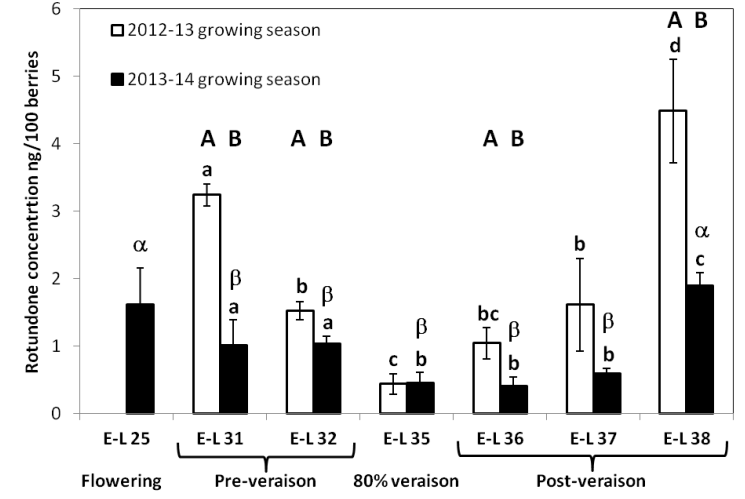

$917 \quad$ Fig. 5. 
Table 1.

\begin{tabular}{|c|c|c|c|c|c|c|}
\hline \multicolumn{7}{|c|}{ The 2012-13 growing season ${ }^{a}$} \\
\hline$w_{p f}^{b}$ & $\begin{array}{l}\text { Berry mass } \\
(\mathrm{g})\end{array}$ & $\begin{array}{l}\mathrm{TSS}^{\mathrm{c}} \\
\left({ }^{\circ} \text { Brix) }\right.\end{array}$ & $\mathrm{pH}$ & $T A^{d}(g / L)$ & $\begin{array}{l}\text { Phenological } \\
\text { stages }^{\mathrm{e}}\end{array}$ & $\begin{array}{c}\text { Sample } \\
\text { description }\end{array}$ \\
\hline 4 & 0.27 & $6.0 \pm 0.2 a$ & $2.37 \pm 0.02 a$ & $31.90 \pm 0.80 \mathbf{a}$ & E-L 31 & $\begin{array}{c}\text { Green pea size } \\
\text { berries }\end{array}$ \\
\hline 6 & 0.40 & $5.4 \pm 0.2 a$ & $2.39 \pm 0.01 a$ & $33.58 \pm 0.95 b$ & E-L 32 & $\begin{array}{c}\text { Green pea size } \\
\text { berries }\end{array}$ \\
\hline 8 & 0.45 & $5.8 \pm 0.0 a$ & $2.52 \pm 0.01 \mathbf{b}$ & $34.40 \pm 0.45 b$ & EL 33-34 & $\begin{array}{l}\text { Most still hard } \\
\text { and green }\end{array}$ \\
\hline 11 & 0.98 & $14.5 \pm 0.2 b$ & $3.05 \pm 0.03 c$ & $10.38 \pm 0.47 c$ & $E-L$ 35-36 & $80 \%$ veraison \\
\hline 13 & 1.02 & $20.1 \pm 0.3 c$ & $3.40 \pm 0.02 d$ & $5.51 \pm 0.30 \mathbf{d}$ & E-L 36 & $\begin{array}{l}\text { Light purple } \\
\text { berries }\end{array}$ \\
\hline 14 & 1.12 & $22.1 \pm 0.4 \mathrm{~d}$ & $3.73 \pm 0.02 \mathbf{e}$ & $4.05 \pm 0.31 \mathrm{e}$ & E-L 37 & Purple berries \\
\hline 16 & 1.01 & $24.5 \pm 0.3 e$ & $3.81 \pm 0.03 f$ & $4.12 \pm 0.10 \mathrm{e}$ & $E-L 37-38$ & $\begin{array}{l}\text { Dark purple } \\
\text { berries }\end{array}$ \\
\hline 18 & 0.99 & $26.3 \pm 1.0 f$ & $3.90 \pm 0.07 \mathrm{~g}$ & $4.00 \pm 0.15 e$ & E-L 38 & $\begin{array}{l}\text { Some berries } \\
\text { slightly shrank }\end{array}$ \\
\hline \multicolumn{7}{|c|}{ The $2013-14$ growing season } \\
\hline wpf & $\begin{array}{l}\text { Berry mass } \\
(\mathrm{g})\end{array}$ & ${ }^{\circ}$ Brix & $\mathrm{pH}$ & $\mathrm{TA}(\mathrm{g} / \mathrm{L})$ & $\begin{array}{l}\text { Phenological } \\
\text { stages }\end{array}$ & $\begin{array}{c}\text { Sample } \\
\text { description }\end{array}$ \\
\hline $0^{f}$ & 0.0049 & & $\mathrm{n} / \mathrm{a}$ & $\mathrm{n} / \mathrm{a}$ & E-L 25-26 & $\begin{array}{c}\text { Flowering } 80 \% \\
\text { caps off }\end{array}$ \\
\hline 4 & 0.18 & $6.3 \pm 0.2$ & $2.82 \pm 0.08 \mathbf{a}$ & $30.58 \pm 0.26 \mathbf{a}$ & E-L 31 & $\begin{array}{c}\text { Green pea size } \\
\text { berries }\end{array}$ \\
\hline 6 & 0.28 & $5.3 \pm 0.2 b$ & $2.76 \pm 0.03 a$ & $32.45 \pm 0.84 b$ & E-L 32 & $\begin{array}{c}\text { Green pea size } \\
\text { berries }\end{array}$ \\
\hline 9 & 0.41 & $7.1 \pm 0.5 c$ & $2.90 \pm 0.03 a$ & $26.70 \pm 0.36 c$ & EL 34-35 & $\begin{array}{l}\text { Begin to colour } \\
\text { and enlarge }\end{array}$ \\
\hline 11 & 0.69 & $15.9 \pm 0.7 \mathbf{d}$ & $3.17 \pm 0.10 b$ & $11.62 \pm 2.33 d$ & E-L 35-36 & $80 \%$ veraison \\
\hline 13 & 0.85 & $19.9 \pm 0.2 \mathbf{e}$ & $3.46 \pm 0.05 c$ & $6.45 \pm 0.52 e$ & E-L 36 & $\begin{array}{l}\text { Light purple } \\
\text { berries }\end{array}$ \\
\hline 15 & 0.95 & $22.9 \pm 0.6 f$ & $3.72 \pm 0.05 d$ & $4.87 \pm 0.35$ ef & E-L 37 & Purple berries \\
\hline 17 & 0.90 & $24.9 \pm 0.3 \mathbf{g}$ & $3.74 \pm 0.09 d$ & $4.20 \pm 0.32 f$ & E-L 38 & $\begin{array}{c}\text { Dark purple } \\
\text { berries }\end{array}$ \\
\hline
\end{tabular}

928

929

930 


\section{Highlights}

932 - Pre-veraison berries contain the highest total terpenoid concentrations

- Berries at different developmental stages have different terpene profiles

- Terpene biosynthesis pathways dictate production patterns during berry

935 development

936

- Rotundone was present in Shiraz flower caps and grapes at both pre-veraison

937 and post-veraison

938

939 